This manuscript is the full version of a Letter to the Editor published in World Psychiatry:

Miloyan, B. \& Fried, E. I. (2017). A reassessment of the relationship between depression and all-cause mortality in 3,604,005 participants from 293 studies. World Psychiatry 16:2, 219-220. DOI: $10.1002 /$ wps.20439.

\title{
A reassessment of the relationship between depression and all-cause mortality in 3,604,005 participants from 293 studies
}

\author{
Beyon Miloyan ${ }^{1,2^{*}} \&$ Eiko Fried $^{3}$ \\ ${ }^{1}$ Department of Mental Health, Bloomberg School of Public Health, Johns Hopkins University \\ ${ }^{2}$ Faculty of Health, Department of Psychology, Federation University Australia \\ ${ }^{3}$ Department of Psychology, University of Amsterdam, Amsterdam, The Netherlands \\ "Corresponding author: b.miloyan@,federation.edu.au
}




\begin{abstract}
The objective of this study is to explain inconsistencies in the relationship between depression and all-cause mortality by performing a reassessment of the included studies of previous systematic reviews. We assessed study-level methodological variables with a focus on sample size and follow-up period, measurement and classification of depression, and model adjustment. We included the constituent studies of fifteen systematic reviews on depression and mortality, yielding 488 articles after the removal of duplicates. 333 studies were extracted, 40 of which used data that overlapped with other included studies. We included 313 estimates from 293 articles in the metaanalysis with a total sample of 3,604,005 participants and over 417,901 deaths. We identified a pronounced publication bias favoring large, positive associations in imprecise studies. Several factors moderated the relationship between depression and mortality. Most importantly, the 16 estimates adjusting for at least one comorbid mental condition (Pooled Effect: 1.08; 95\% CI: 0.981.18), and the fraction of 8 of those estimates also adjusting for health variables (e.g., smoking, alcohol use, or physical inactivity; Pooled Effect: 1.04; 95\% CI: 0.87-1.21), reported considerably smaller associations than the 204 unadjusted estimates (Pooled Effect: 1.32; 95\% CI: 1.28-1.36). The sizable relationship of depression and mortality reported in previous systematic reviews is largely based on low-quality studies; controlling for important covariates attenuates the association considerably. Higher quality studies are needed based on large community samples, extensive follow-up, adjustment for health behaviors and mental disorders, and time-to-event outcomes based on survival analysis methodology.
\end{abstract}




\section{Introduction}

Over three decades of research suggests that depression poses an increased risk for all-cause mortality (1-5), although there is significant uncertainty surrounding this association. Large studies have reported positive (6), negative (7) and lack of associations (8), and there is striking variation in the overall effect estimates of extant systematic reviews (ranging from $17 \%$ to $161 \%$ ) $(9,10)$. To better inform clinical decision-making and evidence-based service provision, it is crucial to resolve these discrepancies.

Although important shortcomings of prior studies, such as small sample sizes (11), brief followup periods $(12,13)$ and predominantly unadjusted estimates (14) have been acknowledged, comprehensive efforts have not focused on synthesizing the literature with respect to these methodological variables. Also of particular interest are issues related to the measurement and classification of depression, and data analytic approaches. First, a large number of instruments and clinical definitions are used to diagnose depression, and these instruments differ considerably in symptom content (15), suggesting that a careful analysis of this issue is needed. Second, depression appears to have bidirectional associations with smoking and drinking (16-19). Finally, depression frequently co-occurs with other mental disorders $(18,20,21)$, which have also been found to be associated with mortality $(5,22)$. The lack of adjustment for health variables and comorbid mental conditions in previous systematic reviews suggests that the association between depression and mortality may be confounded and inflated in the literature.

The aim of the present paper is to explain inconsistencies in the current evidence base by providing a comprehensive reassessment of the constituent studies of previous systematic reviews, with a focus on important methodological issues that may impact the relationship between depression and mortality. We further seek to explore whether estimates of the relationship between depression and mortality on the basis of the methodologically most rigorous studies differed from those of previous meta-analyses.

\section{Methods}

\section{Search Strategy}

The sample of studies was drawn from 15 systematic reviews that assessed the relationship between depression and mortality, in September, 2016 (See Table 1). 


\section{Study Selection}

Studies that assessed depression at baseline and all-cause mortality at follow-up were included. Studies were excluded if they did not assess depression as exposure or all-cause mortality as outcome, or if depressed and control participants were drawn from separate samples. Following a removal of all duplicate records, BM examined each study abstract against the inclusion and exclusion criteria. See Figure 1 for a flow chart of included studies.

Table 1. Characteristics of the included systematic reviews.

\begin{tabular}{|c|c|c|c|c|}
\hline Study & Selection & $\begin{array}{l}\text { Number } \\
\text { of Studies }\end{array}$ & $\begin{array}{l}\text { Result } \\
\text { (Depressed vs. } \\
\text { Control) }\end{array}$ & $\begin{array}{l}\text { Publication } \\
\text { Bias }\end{array}$ \\
\hline $\begin{array}{l}\text { Barth et } \\
\text { al. } 2004 \\
\text { (10) }\end{array}$ & $\begin{array}{l}\text { Prospective studies of patients } \\
\text { with coronary heart disease } \\
\text { assessing depression at baseline } \\
\text { and mortality at follow-up }\end{array}$ & 20 & $\begin{array}{l}\text { Follow-up period } \\
<6 \text { months: } \\
\text { Pooled HR: } \\
\text { 2.07; 95\% CI: } \\
0.82-5.26 \\
\text { Follow-up period } \\
>6 \text { months and } \\
<2 \text { years: } \\
\text { Pooled HR: } \\
2.61 ; 95 \% \mathrm{CI} \text { : } \\
1.53-4.47\end{array}$ & Yes \\
\hline $\begin{array}{l}\text { Bartoli et } \\
\text { al. } 2013 \\
\text { (23) }\end{array}$ & $\begin{array}{l}\text { Studies assessing post-stroke } \\
\text { depression at baseline and } \\
\text { mortality at follow-up }\end{array}$ & 13 & $\begin{array}{l}\text { Pooled HR: } 1.52 \\
(95 \% \text { CI: } 1.02- \\
2.26)\end{array}$ & No \\
\hline $\begin{array}{l}\text { Cuijpers } \\
\text { et al. } \\
2002(24)\end{array}$ & $\begin{array}{l}\text { Studies based on random, } \\
\text { community samples comparing } \\
\text { mortality between those with and } \\
\text { without depression }\end{array}$ & 25 & $\begin{array}{l}\text { Pooled RR: } 1.81 \\
(95 \% \text { CI: } 1.58- \\
2.07)\end{array}$ & No \\
\hline $\begin{array}{l}\text { Cuijpers } \\
\text { et al. } \\
2014(12)\end{array}$ & $\begin{array}{l}\text { Prospective studies assessing } \\
\text { depression at baseline and all- } \\
\text { cause mortality at follow-up }\end{array}$ & 293 & $\begin{array}{l}\text { Pooled RR: } 1.52 \\
(95 \% \text { CI: } 1.45- \\
1.59)\end{array}$ & Yes \\
\hline
\end{tabular}




\begin{tabular}{|c|c|c|c|c|}
\hline $\begin{array}{l}\text { Nicholson } \\
\text { et al. } \\
2006 \text { (14) }\end{array}$ & $\begin{array}{l}\text { Prospective cohort studies of } \\
\text { patients with coronary heart } \\
\text { disease reporting the association } \\
\text { between depression and mortality }\end{array}$ & 34 & $\begin{array}{l}\text { Pooled RR: } 1.53 \\
\text { (95\% CI: } 1.11- \\
2.10)\end{array}$ & Yes \\
\hline $\begin{array}{l}\text { Park et al. } \\
2013 \text { (25) }\end{array}$ & $\begin{array}{l}\text { Prospective studies reporting } \\
\text { Hazard Ratios of the association } \\
\text { between depression at baseline } \\
\text { and all-cause mortality as } \\
\text { outcome in patients with diabetes }\end{array}$ & 10 & $\begin{array}{l}\text { Pooled HR: } 1.50 \\
\text { (95\% CI: } 1.35- \\
1.66)\end{array}$ & No \\
\hline $\begin{array}{l}\text { Pinquart } \\
\text { et al. } \\
2010 \text { (9) }\end{array}$ & $\begin{array}{l}\text { Studies assessing the relationship } \\
\text { between depression and mortality } \\
\text { in cancer patients }\end{array}$ & 76 & $\begin{array}{l}\text { Pooled RR: } 1.17 \\
(95 \% \text { CI: } 1.12- \\
1.22)\end{array}$ & No \\
\hline $\begin{array}{l}\text { Satin et } \\
\text { al. } 2009 \\
(26)\end{array}$ & $\begin{array}{l}\text { Studies assessing the relationship } \\
\text { between post-cancer depression } \\
\text { and mortality }\end{array}$ & 27 & $\begin{array}{l}\text { Pooled RR: } 1.25 \\
(95 \% \text { CI: } 1.12- \\
1.40)\end{array}$ & No \\
\hline $\begin{array}{l}\text { Saz et al. } \\
2001 \text { (27) }\end{array}$ & $\begin{array}{l}\text { Studies assessing the relationship } \\
\text { between depression and mortality } \\
\text { in older community samples }\end{array}$ & 45 & $\begin{array}{l}\text { Pooled OR: } 1.73 \\
(95 \% \text { CI: } 1.53- \\
1.95)\end{array}$ & No \\
\hline $\begin{array}{l}\text { Sokoreli } \\
\text { et al. } \\
2016(28)\end{array}$ & $\begin{array}{l}\text { Studies assessing the relationship } \\
\text { between depression and mortality } \\
\text { among heart failure patients }\end{array}$ & 26 & $\begin{array}{l}\text { Pooled HR: } 1.57 \\
\text { (95\% CI: } 1.30- \\
1.89)\end{array}$ & Yes \\
\hline $\begin{array}{l}\text { Sørensen } \\
\text { et al. } \\
2005 \text { (11) }\end{array}$ & $\begin{array}{l}\text { Studies assessing the relationship } \\
\text { between post-myocardial } \\
\text { infarction depression and } \\
\text { mortality }\end{array}$ & 31 & $\begin{array}{l}\text { Quantitative } \\
\text { synthesis not } \\
\text { reported }\end{array}$ & Yes \\
\hline $\begin{array}{l}\text { Van } \\
\text { Dooren et } \\
\text { al. } 2013 \\
\text { (29) }\end{array}$ & $\begin{array}{l}\text { Studies assessing the association } \\
\text { between depression and mortality } \\
\text { among patients with diabetes }\end{array}$ & 16 & $\begin{array}{l}\text { Pooled HR: } 1.46 \\
(95 \% \text { CI: } 1.29- \\
1.66)\end{array}$ & Yes \\
\hline $\begin{array}{l}\text { Van } \\
\text { Melle et } \\
\text { al. } 2004 \\
(30)\end{array}$ & $\begin{array}{l}\text { Studies assessing the association } \\
\text { between post-myocardial } \\
\text { infarction depression and } \\
\text { mortality }\end{array}$ & 14 & $\begin{array}{l}\text { Pooled OR: } 2.38 \\
(95 \% \text { CI: } 1.76- \\
3.22)\end{array}$ & No \\
\hline
\end{tabular}




\begin{tabular}{|c|c|c|c|c|}
\hline $\begin{array}{l}\text { Walker et } \\
\text { al. } 2015 \\
\text { (13) }\end{array}$ & $\begin{array}{l}\text { Studies assessing the association } \\
\text { between diagnosed mental } \\
\text { disorders and mortality }\end{array}$ & 43 & $\begin{array}{l}\text { Pooled RR: } 1.71 \\
(95 \% \mathrm{CI}: 1.54- \\
1.90)\end{array}$ & No \\
\hline $\begin{array}{l}\text { Wulsin et } \\
\text { al. } 1999 \\
(31)\end{array}$ & $\begin{array}{l}\text { Studies assessing the association } \\
\text { of depression with mortality }\end{array}$ & 57 & $\begin{array}{l}\text { Quantitative } \\
\text { synthesis not } \\
\text { reported }\end{array}$ & Yes \\
\hline
\end{tabular}

\section{Data Extraction}

BM independently extracted information about sample size and characteristics, measurement of depression, study design, model adjustment, follow-up period, number of deaths, and effect estimates. EF independently extracted the same information from a random sample of $10 \%$ of the included papers in order to assess inter-rater agreement. Thirty-five estimates from thirty studies were compared, and two differences were resolved through discussion. We contacted authors of included records by email to obtain further information when needed. Multiple estimates were included from a single study if the participants that comprised each group were not overlapping. If there were overlapping estimates, then only the most inclusive estimate was retained to avoid collinearity, meaning that we opted for the most adjusted estimate, the estimate derived using the longest follow-up period, or using the cutoff score with the best overall psychometric properties against diagnostic interviews. Seventy-four unadjusted risk ratios (RR) were calculated manually based on the raw numbers reported in each paper, or based on information provided by the authors. RRs were calculated manually either when a formal estimate was missing, or when reported estimates were based on unique subgroups within the sample (e.g., depressed patients scoring in the lower tercile on a cognitive test relative to those without depression or cognitive impairment).

\section{Meta-Analyses}

Effect estimates were categorized according to study characteristics. Random-effects metaanalysis models were used to estimate pooled effect estimates for the sub-groups of interest (32). The $\mathrm{I}^{2}$ statistic was used to estimate the percentage of the total variation in effect sizes attributable to heterogeneity between studies in each analysis (33); $\mathrm{I}^{2}$ values range from 0 to $100 \%$, and values above $50 \%$ are typically considered to be indicative of substantial heterogeneity. 


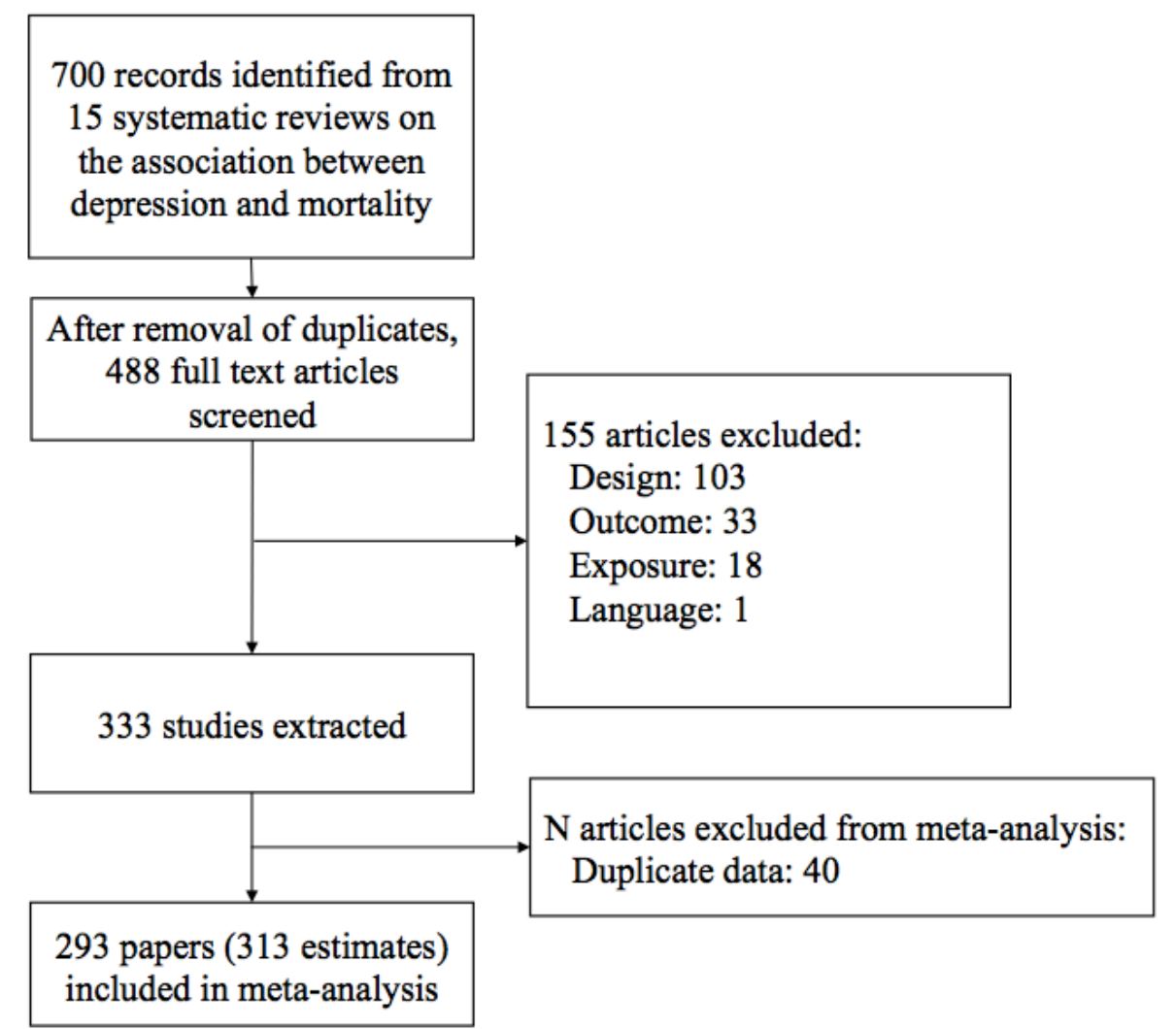

Figure 1. Flow chart of included studies.

Analyses were conducted according to adjustment for mental disorders (at least one of the most prevalent co-occurring conditions: anxiety, substance use disorder, or psychosis), health behaviors (at least one of smoking, drinking, drug use and physical activity) and overall adjustment for one or more variables (crude or adjusted estimates), sample size, number of deaths, follow-up periods and differences between instruments. Egger's test was used to indicate whether there was a bias of effect estimates (natural log of the effect estimates) relative to the precision of those estimates (standard error of the log of the effect estimates) (34). An intercept of zero indicates that there is no publication bias. Studies that employed continuous depression scores were excluded from all of the analyses that classified depression as present or absent because of differences in the meaning of the coefficients. Finally, interactions were computed in order to compare pooled estimates derived from separate subgroups of interest (e.g., to compare estimates derived from male versus female samples) (35). 


\section{Results}

\section{Descriptive Analysis}

The literature search yielded 700 articles from 15 systematic reviews. After removal of duplicate records (i.e., identical studies appearing in different systematic reviews), 488 articles were screened for meeting study criteria. 333 eligible articles were extracted (see Supplementary File 1 for study characteristics). Of those, 40 studies were excluded from the meta-analysis because of overlapping data with other articles, and one study was excluded due to missing estimates that we were unable to obtain. Three hundred and thirteen estimates from 293 articles were included in the final meta-analysis, consisting of 3,604,005 participants and over 417,901 deaths.

\section{Publication Bias}

A funnel plot and results of Egger's test suggested a pronounced publication bias as indicated by the positive intercept $(1.02 ; 95 \% \mathrm{CI}: 0.72-1.31)$ of effect estimates on their standard errors favoring imprecise studies with large, positive associations (see Figure 2).

Studies with small samples showed a larger variation and magnitude of effect estimates. The inverse relationship between sample and effect sizes was apparent both when using total sample size (see Figure 3, Panel A) and number of deaths as indicators (see Figure 3, Panel B). Number of deaths, contingent on sample size and follow-up period, appeared to be more sensitive to differences in effect estimates than sample size alone.

There was also larger variation in and overall magnitude of effect estimates based on studies with follow up periods with approximately 5 years or fewer (see Figure 4). Overall, the pronounced publication bias we identified contrasts with the conclusions of most prior systematic reviews (see final column in Table 1).

\section{Sample Type}

One-hundred and ninety-one estimates were based on medical samples, 82 on community samples, 4 on veteran samples, and 5 ("other") estimates did not fall into any of these categories. We did not observe differences in effect estimates between sample types, however there was considerable heterogeneity within each of the aforementioned categories. 


\section{Sex Differences}

Thirty-three estimates in this study were based on male samples, and 29 on female samples, excluding the studies that employed continuous depression scores. The interaction of the effect estimates derived from male $\left(1.41 ; 95 \% \mathrm{CI}: 1.29-1.54 ; \mathrm{I}^{2}=82 \%\right)$ and female $(1.23 ; 95 \% \mathrm{CI}$ : 1.13 $1.32 ; \mathrm{I}^{2}=47 \%$ ) samples suggested that there is a small sex difference in the risk of mortality attributable to depression (Relative Effect: 1.15; 95\% CI: 1.02-1.29) such that any association between depression and mortality is stronger in males.

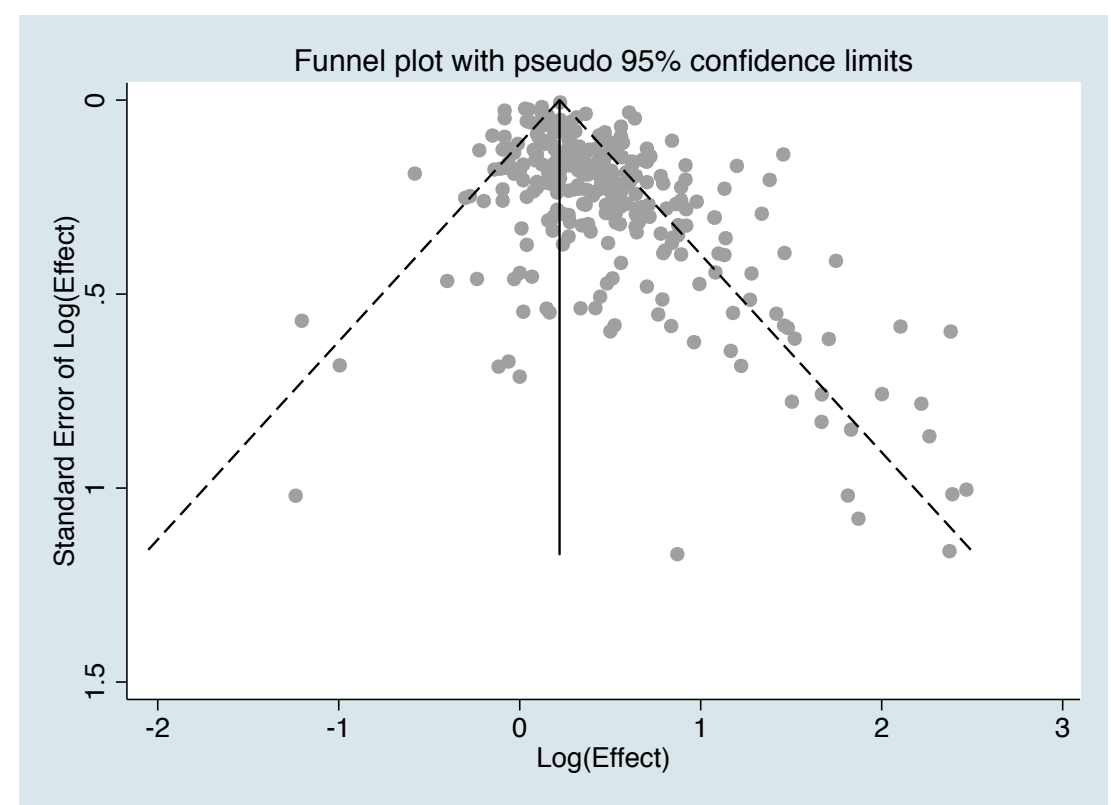

Figure 2. Funnel plot of the relationship between effect estimates (on the natural log scale) and the standard error of the natural log of effect estimates, indicating a pronounced publication bias for studies with positive associations. 

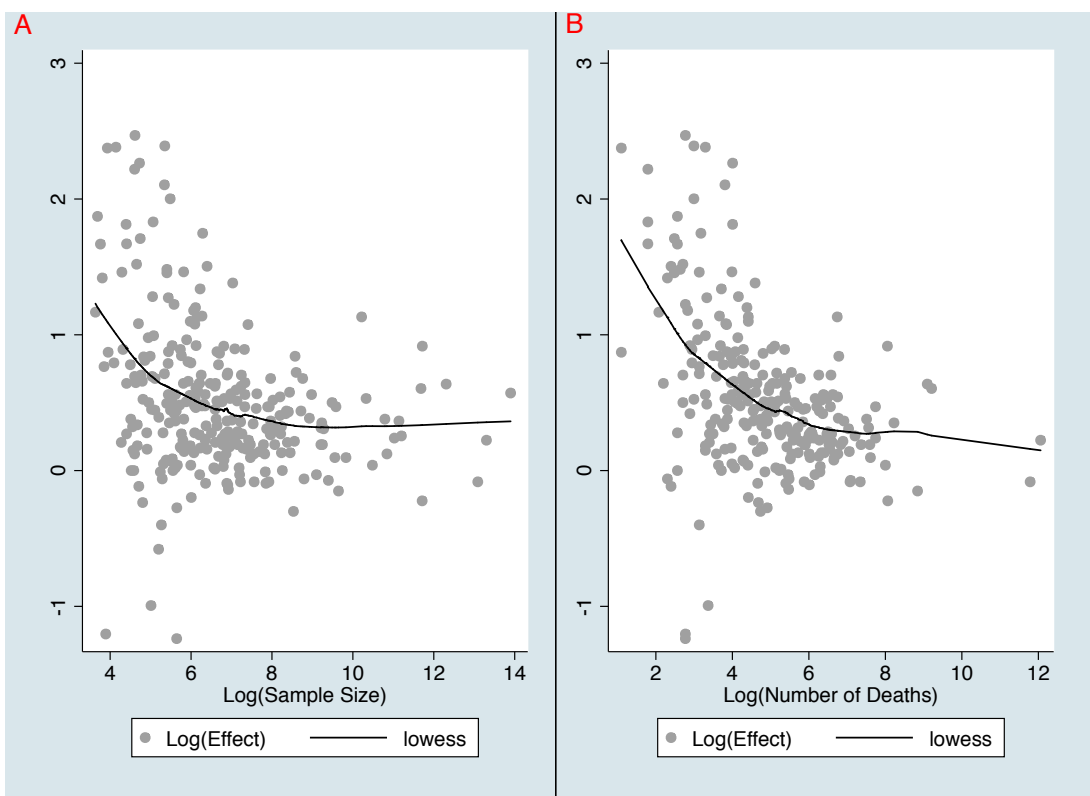

Figure 3. Scatterplots of the relationship between effect estimates and (a) sample size, and (b) number of deaths with locally weighted smoothing (lowess). All variables are on the natural $\log$ scale.

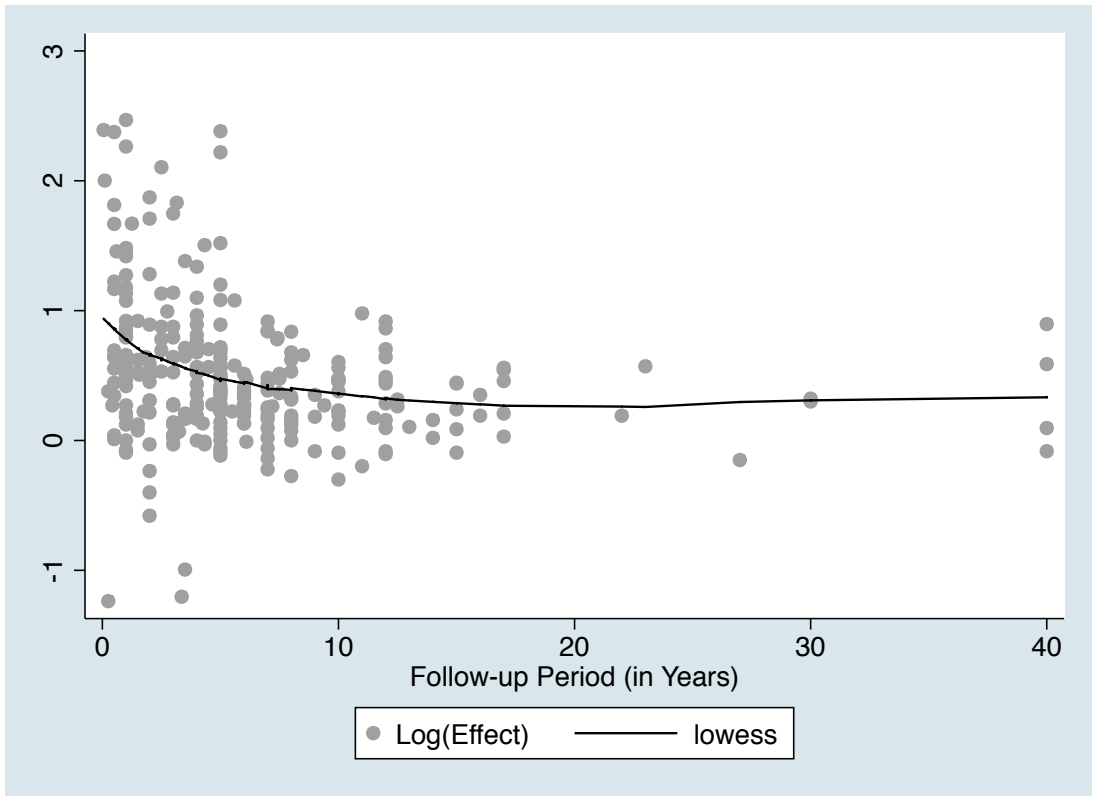

Figure 4. Scatterplot of the relationship between effect estimates (on the natural log scale) and length of follow-up period with locally weighted smoothing (lowess). 


\section{Diagnostic Measures}

Two hundred and eighteen estimates were obtained on the basis of self-report questionnaires, 31 of which employed continuous scores; 57 were based on diagnostic interviews; 20 on data from registers; and 18 on a combination of instruments.

\section{Diagnostic Interviews}

The overall effect estimate among 53 studies that used diagnostic interviews was 1.41 (95\% CI: 1.25-1.56; $\left.\mathrm{I}^{2}: 65 \%\right)$. The 18 estimates that used structured interviews developed based on DSM criteria (sometimes considered "gold standard" instruments) were more consistent (Pooled Effect: 1.21; 95\% CI: $0.99-1.43 ; \mathrm{I}^{2}=36 \%$ ) than the 35 estimates from the rest of the interviews (Pooled Effect: $1.47,95 \%$ CI: $1.26-1.68 ; \mathrm{I}^{2}=69 \%$ ).

\section{Self-Report Questionnaires}

Of the 218 estimates based on self-report questionnaires, 48 were based on the Center of Epidemiological Studies - Depression Scale (CES-D), 31 on the Beck Depression Inventory (BDI), 30 on the Geriatric Depression Scale (GDS), 29 on the Hospital Anxiety and Depression Scale (HADS), and 11 on the 9-item Patient Health Questionnaire (PHQ-9). Among studies that used the same questionnaire, in many cases different or modified versions were used. Even studies that used the same version of the same questionnaire frequently used different cutoff scores to distinguish those with and without depression. Apart from the self-report questionnaires above, at least 40 other scales were used to measure depression, none of which had more than a few estimates. In sum, we identified differences between scales and inconsistencies among studies using the same scales and cutoff scores in estimates of mortality risk among individuals with depression versus controls, although the estimates were too few to adjust adequately for other study characteristics.

\section{Continuous Scores}

Finally, the pooled estimate of the 31 studies that used continuous scores suggested that there is a $3-6 \%$ increase in the risk of death per point increase of depression score averaged across the different instruments used to measure depression (1.05; 95\% CI: $\left.1.03-1.06 ; \mathrm{I}^{2}: 76 \%\right)$. These estimates were analyzed separately from the binary measures of depression because of differences in the meaning of the coefficients. There was evidence of publication bias among the studies that 
used continuous depression scores as indicated by the positive intercept of the effect estimates on their standard errors $(2.27 ; 95 \% \mathrm{CI}: 1.31-3.24)$.

\section{Model Adjustment}

We investigated potential differences between adjusted and unadjusted studies in four scenarios: any adjustment, adjustment for health behaviors only, adjustment for mental disorders only, and adjustment for both health behaviors and mental disorders.

The pooled effect of the 177 estimates based on overall adjusted models (1.30; 95\% CI: 1.26-1.35; $\mathrm{I}^{2}=79 \%$ ) was indistinguishable from the pooled effect of the 105 estimates based on overall unadjusted models (1.34; 95\% CI: 1.26-1.43; $\left.\mathrm{I}^{2}=63 \%\right)$. Most of these estimates were adjusted only for sociodemographic variables. The pooled effects of the 70 estimates that were adjusted for health behaviors $\left(1.28 ; 95 \% \mathrm{CI}: 1.22-1.35 ; \mathrm{I}^{2}=75 \%\right)$ and the 212 estimates that were unadjusted for health behaviors $\left(1.33 ; 95 \% \mathrm{CI}: 1.28-1.37 ; \mathrm{I}^{2}=74 \%\right)$ were also indistinguishable. However, the pooled effect of the 16 estimates that were adjusted for mental disorders (1.08; 95\% CI: 0.98-1.18; $\left.\mathrm{I}^{2}=52 \%\right)$ was smaller than the pooled effect of the 266 estimates that did not $(1.33 ; 95 \%$ CI: 1.29 $1.37 ; \mathrm{I}^{2}=86 \%$ ) adjust for mental disorders (Relative Effect: $\left.0.81 ; 95 \% \mathrm{CI}: 0.74-0.90\right)$. Finally, there was no evidence of an association between depression and all-cause mortality among the eight estimates that adjusted for both mental disorders and health behaviors (Pooled Effect: 1.04; 95\% CI: $0.87-1.21 ; \mathrm{I}^{2}=50 \%$ ).

\section{Sensitivity Analysis}

Structured diagnostic interviews based on DSM criteria are generally considered the "gold standard" for diagnosing Major Depression. There were only 18 estimates based on diagnostic DSM-based interviews in this study. Seven were based on the Diagnostic Interview Schedule (DIS), 4 on the Structured Clinical Interview for the DSM (SCID), 4 on the Comprehensive International Diagnostic Interview (CIDI), 2 on the Schedules for Clinical Assessment in Neuropsychiatry (SCAN) and 1 was based on the M.I.N.I. International Neuropsychiatric Interview (MINI). Thirteen out of these 18 studies were based on time-to-event outcomes using Hazard Ratio (HR) estimates, and a fraction of four on community samples. We consider these three desirable attributes of studies addressing the relationship between depression and mortality, but found only four estimates (about $1 \%$ of all studies) with the conjunction of these features. The overall HR was 1.17 (95\% CI: 0.75-1.60; $\mathrm{I}^{2}=58 \%$ ), which is not indicative of a strong association between depression and mortality. 


\section{Discussion}

We reassessed the constituent studies of 15 systematic reviews on the association between depression and all-cause mortality. The purpose of this reassessment was to better understand the composition of studies that have sought to address this relationship, delineate some apparent methodological reasons for heterogeneity between studies, and to explore whether estimates of the relationship between depression and mortality on the basis of the methodologically most rigorous studies differed from those of previous meta-analyses. Overall, we draw 5 main conclusions.

First, studies that control for important covariates consistently report smaller effects than other studies. Among studies that controlled for health behaviors and co-occurring mental disorders, we do not find that depression poses an increased risk for mortality. This observation differs markedly from all but two $(11,14)$ of the systematic reviews on which the present study was based: the other thirteen concluded that there is an increased risk of mortality attributable to depression. Only eight estimates (or less than 3\% of all of the studies in our review) adjusted for comorbid mental disorders as well as smoking or drinking. The pooled estimate of these studies was of considerably lower magnitude than most of the other estimates. This points to a major limitation of the literature, given that more than half of individuals diagnosed with Major Depressive Disorder suffer from at least one additional comorbid disorder $(20,36)$, which have been found to have negative sequelae. Given the small number of adequately adjusted studies in this domain, strong conclusions are unwarranted at present, and future studies are urgently needed that adjust at least for past and present health behaviors and mental disorders in addition to typical sociodemographic characteristics.

Second, there was evidence of a publication bias, such that large, positive associations were generally imprecise. The largest estimates in this review consistently came from studies with small samples and short follow-up durations. The observed publication bias may be exacerbated by the fact that many depression symptoms that constitute diagnosis are shared with various physical conditions: The larger effects seen in studies with shorter follow-up durations may be indicative of confounding by reverse causality among individuals who are physically unwell at baseline. Indeed, many depression instruments assess a variety of physical symptoms (15). The DSM-IV / DSM-5 criteria for Major Depression, for instance, contain fatigue, weight/appetite changes, psychomotor problems, and sleep problems that are unspecific to depression and may pick up on comorbid medical conditions (37) or even side-effects of medication use for preexisting conditions. After all, over two-thirds of the analyses that we investigated were conducted using medical samples. 
Third, among the 293 studies that were included in this review, more than 50 different instruments were used to assess depression severity, and most of these were self-report questionnaires. Although some of the most common questionnaires were used in many studies, over 40 questionnaires were each used by no more than a handful of studies. This finding is remarkable and raises pressing questions about the operationalization of depression: imagine 50 different definitions were used to diagnose breast cancer, measles, or a fever. There remains a lack of a true gold standard instrument, and depression scales differ considerably in symptom content. A recent study identified 52 disparate symptoms in 7 commonly used scales; $40 \%$ of the 52 symptoms appeared in only one scale, and the CES-D had by far the lowest overlap with other scales (33\% of the CES-D symptoms do not appear in any other scale) (15). Given this content heterogeneity, it is not surprising that depression scales are often only moderately correlated and can lead to different results (38-40). Studies that assess for (in)consistencies between several rating scales in the same sample could assess for heterogeneity attributable to instrumentation, and perhaps take corrective measures (41).

Fourth, even among studies that applied the same questionnaires, we identified a variety of cutoff scores that were used to distinguish between individuals with and without depression. When we employed the most commonly used cutoff scores for each of the most commonly used questionnaires (the BDI, CES-D, HADS, GDS-15 and PHQ-9) to attain classification consistency with sizable samples, there remained substantial heterogeneity between studies. We believe that these inconsistencies are indicative of more general challenges to measurement and classification of depression, particularly on the basis of self-report questionnaires. For example, several validation studies of the same depression scales recommend using different cutoff scores (42-49).

Finally, studies that employed structured diagnostic interviews based on DSM criteria (often considered "gold standard" instruments) were quite consistent. Although imperfect, these instruments may somewhat minimize confounding with comorbid physical conditions inasmuch as respondents are required to endorse the DSM core symptoms of depression prior to assessing for more general physical, somatic and cognitive symptoms. Questionnaires that treat all manner of symptoms as exchangeable by forming depression groups whose sum scores exceed a threshold may, on the other hand, be supporting the biased inclusion of individuals who are of relatively poorer health (and not necessarily depressed) at baseline.

\section{Summary and conclusion}

Despite extensive research on the association between depression and mortality, the overall quality of the literature that we reassessed is poor: Only $27 \%$ of estimates were based on community 
samples (i.e. without selection for preexisting physical conditions), only $20 \%$ of estimates were based on follow-up periods of 10 years or more, only $6 \%$ of estimates were based on structured diagnostic interviews based on DSM criteria, and only 3\% were based on adjustment for mental disorders and health behaviors. A consistent pattern that we observed is that among the studies of higher quality - large sample size, extensive follow-up periods, proper diagnostic measures, adjustment for mental disorders, health behaviors and time-to-event outcomes using survival analysis - associations were either considerably weaker than in prior meta-analyses, or nonexistent. Unfortunately, studies were too few in number to draw any strong conclusions: only a single estimate (8) in this study was based on the conjunction of all of the aforementioned features. We conclude that the estimates of previous systematic reviews are likely inflated, given substantial publication bias and lack of thorough research designs. Another issue is the interaction of three points: depression scales encompass physical symptoms that overlap with comorbid conditions, comorbidities are often not controlled for, and most studies to date have been carried out in medical samples.

Given the available evidence, it thus seems premature to conclude that depression poses a considerable risk for mortality. More work is required to examine what variables related to depression and mortality may modify this relationship. For example, evidence points to a key mediating role of health behaviors such as smoking, drinking and physical inactivity in explaining the risk of adverse cardiovascular outcomes among depressed individuals (50,51). This could plausibly account for a variety of adverse health outcomes that are not limited to cardiovascular disorders, and also explain why estimates that did not adjust for health behaviors and co-occurring mental disorders - also associated with poor health behaviors (18) - were found to report much larger effects in this study. Relatedly, the prevalence of substance disorders is higher among males $(52,53)$, and may contribute to the sex differences in mortality risk observed in this study. The frequent observation of low socioeconomic status among depressed individuals $(54,55)$ further suggests the possibility that the risk of developing depression and premature mortality are both influenced by the same preceding variables. For example, smoking and alcohol use at baseline are both associated with increased risk of depression onset at follow-up $(17,56)$. These health behavior characteristics, also frequently observed among low SES individuals, strongly mediate the relationship between SES and all-cause mortality (57). It is crucial for future research to disentangle these complex relationships and potential interactions among predictors and mediators.

\section{Strengths and limitations}

We have provided a detailed reassessment of the constituent studies of 15 systematic reviews that addressed the relationship between depression and mortality, in what we believe is the most 
comprehensive analysis of the literature to date. The present work is to our knowledge the first detailed attempt to explain inconsistencies in the literature in terms of measurement challenges and adjustment for substantive variables. The Supplementary File contains all of the extracted data of the studies in this reassessment; we hope this will provide future studies with crucial resources to better understand the relationship between depression and mortality.

There are several limitations to the present work that must be noted. First, this study is a reassessment of 15 systematic reviews - a meta-analysis would likely have uncovered further empirical work such as newer studies that emerged after the most recent systematic reviews were published. A second limitation of this study may pertain to the exclusive focus on all-cause mortality, preventing the ability to rule out whether depression poses differential risk for some specific causes of mortality. For example, over 30 years of research suggests that suicide is associated with aspects of depression $(58,59)$, and recent studies continue to report powerful associations between depression and suicide (5). We do not believe that the absence of causespecific mortality in this analysis is a limitation of the present work, but rather a subject for separate research: while studies of cause-specific mortality may be helpful for understanding possible reasons of death among depressed individuals, all-cause mortality is useful for addressing questions about the overall public health significance of depression. Additionally, there are methodological grounds for treating these topics separately. First, most of the research on causespecific mortality (and particularly, suicide) is that such studies typically start by identifying individuals who died of a particular cause, and then assess whether depression was likelier to occur during the lifetime of these individuals. What these studies should do is assess the relationship between depression at baseline and suicidal mortality at follow up in random, population-based samples followed prospectively. The reason this is uncommon (and usually not feasible) is because of the low incidence of suicidal deaths in the population, however a consequence of this is that most available studies do not meet basic methodological requirements. Additionally, and as previously alluded to, a rigorous investigation of the association between depression and suicide mortality needs to appropriately address the possible confounding role of health behaviors such as smoking, drug use and physical inactivity that have also been found to be associated with suicide in retrospective studies (60-64). Finally, despite the large number of included studies, there were only a few high-quality studies in the major categories of interest. The first consequence of this limitation is that we do not have many studies contributing to our pooled estimates for the subgroups of interest, and the second is that we could not adequately parcel out the association of related study characteristics when assessing a methodological variable of interest. For instance, we found no association between depression and mortality in the 8 studies that controlled for both health variables and comorbid conditions, but it is possible that this lack of association is driven by other factors. Nonetheless, and despite these limitations, we believe that the approach taken in 
the present study provides (a) better insights than simply pooling all constituent estimates, due to the large publication bias and heterogeneity in the literature, and (b) is of sufficient quality to raise serious questions about the nature of the relationship between depression and all-cause mortality due to the poor quality of the literature. 


\section{References}

1. Martin RL, Cloninger CR, Guze SB, Clayton PJ. Mortality in a Follow-up of 500 Psychiatric Outpatients: II. Cause-Specific Mortality. Arch Gen Psychiatry. 1985 Jan 1;42(1):58-66.

2. Buchholtz-Hansen PE, Wang AG, Kragh-Sørensen P, the Danish University Antidepressant Group. Mortality in major affective disorder: relationship to subtype of depression. Acta Psychiatr Scand. 1993 May 1;87(5):329-35.

3. Brodaty H, MacCuspie-Moore CM, Tickle L, Luscombe G. Depression, diagnostic subtype and death: a 25 year follow-up study. J Affect Disord. 1997 Dec;46(3):233-42.

4. Brådvik L, Berglund M. Late mortality in severe depression. Acta Psychiatr Scand. 2001 Feb 1;103(2):111-6.

5. Chesney E, Goodwin GM, Fazel S. Risks of all-cause and suicide mortality in mental disorders: a meta-review. World Psychiatry Off J World Psychiatr Assoc WPA. 2014 Jun;13(2):153-60.

6. Markkula N, Härkänen T, Perälä J, Partti K, Peña S, Koskinen S, et al. Mortality in people with depressive, anxiety and alcohol use disorders in Finland. Br J Psychiatry J Ment Sci. 2012 Feb;200(2):143-9.

7. Chwastiak LA, Rosenheck RA, Desai R, Kazis LE. Association of psychiatric illness and all-cause mortality in the National Department of Veterans Affairs Health Care System. Psychosom Med. 2010 Oct;72(8):817-22.

8. Eaton WW, Roth KB, Bruce M, Cottler L, Wu L, Nestadt G, et al. The Relationship of Mental and Behavioral Disorders to All-Cause Mortality in a 27-Year Follow-up of 4 Epidemiologic Catchment Area Samples. Am J Epidemiol. 2013 Nov 1;178(9):1366-77.

9. Pinquart M, Duberstein PR. Depression and cancer mortality: A meta-analysis. Psychol Med. 2010;40:1797-810.

10. Barth J, Schumacher M, Herrmann-Lingen C. Depression as a risk factor for mortality in patients with coronary heart disease: a meta-analysis. Psychosom Med. 2004 Dec;66(6):802-13.

11. Sørensen P, Friis-Hasché E, Haghfelt T, Bech P. Postmyocardial infarction mortality in relation to depression: A systematic critical review. Psychhotherapy Psychosom. 2005;74:69-80.

12. Cuijpers P, Vogelzangs N, Twisk J, Kleiboer A, Li J, Penninx BW. Comprehensive metaanalysis of excess mortality in depression in the general community versus patients with specific illnesses. Am J Psychiatry. 2014;171:453-462. 
13. Walker ER, McGee RE, Druss BG. Mortality in mental disorders and global disease burden implications: a systematic review and meta-analysis. JAMA Psychiatry. 2015 Apr;72(4):334-41.

14. Nicholson A, Kuper H, Hemingway H. Depression as an aetiologic and prognostic factor in coronary heart disease: a meta-analysis of 6362 events among 146538 participants in 54 observational studies. Eur Heart J. 2006 Dec;27(23):2763-74.

15. Fried EI. The 52 symptoms of major depression: Lack of content overlap among seven common depression scales. J Affect Disord. 2017 Jan 15;208:191-7.

16. Fluharty M, Taylor AE, Grabski M, Munafò MR. The Association of Cigarette Smoking With Depression and Anxiety: A Systematic Review. Nicotine Tob Res. 2017 Jan 1;19(1):3-13.

17. Mojtabai R, Crum RM. Cigarette Smoking and Onset of Mood and Anxiety Disorders. Am J Public Health. 2013 Jan 17;103(9):1656-65.

18. Grant BF, Stinson FS, Dawson DA, Chou SP, Dufour MC, Compton W, et al. Prevalence and Co-occurrence of Substance Use Disorders and IndependentMood and Anxiety Disorders: Results From the National Epidemiologic Survey on Alcohol and RelatedConditions. Arch Gen Psychiatry. 2004 Aug 1;61(8):807-16.

19. Taylor G, McNeill A, Girling A, Farley A, Lindson-Hawley N, Aveyard P. Change in mental health after smoking cessation: systematic review and meta-analysis. BMJ. 2014 Feb 13;348:g1151.

20. Kessler RC, Chiu WT, Demler O, Merikangas KR, Walters EE. Prevalence, severity, and comorbidity of 12-month DSM-IV disorders in the National Comorbidity Survey Replication. Arch Gen Psychiatry. 2005 Jun;62(6):617-27.

21. Davis L, Uezato A, Newell JM, Frazier E. Major depression and comorbid substance use disorders. Curr Opin Psychiatry. 2008 Jan;21(1):14-8.

22. Roerecke M, Rehm J. Alcohol use disorders and mortality: a systematic review and metaanalysis. Addict Abingdon Engl. 2013 Sep;108(9):1562-78.

23. Bartoli F, Lillia N, Lax A, Crocamo C, Mantero V, Carr\&\#xe0, et al. Depression after Stroke and Risk of Mortality: A Systematic Review and Meta-Analysis. Stroke Res Treat. 2013 Mar 7;2013:e862978.

24. Cuijpers P, Smit F. Excess mortality in depression: a meta-analysis of community studies. J Affect Disord. 2002 Dec;72(3):227-36.

25. Park M, Katon WJ, Wolf FM. Depression and risk of mortality in individuals with diabetes: a meta-analysis and systematic review. Gen Hosp Psychiatry. 2013 Jun;35(3):217-25. 
26. Satin JR, Linden W, Phillips MJ. Depression as a predictor of disease progression and mortality in cancer patients: a meta-analysis. Cancer. 2009 Nov 15;115(22):5349-61.

27. Saz P, Dewey ME. Depression, depressive symptoms and mortality in persons aged 65 and over living in the community: a systematic review of the literature. Int J Geriatr Psychiatry. 2001 Jun;16(6):622-30.

28. Sokoreli I, de Vries JJG, Pauws SC, Steyerberg EW. Depression and anxiety as predictors of mortality among heart failure patients: systematic review and meta-analysis. Heart Fail Rev. 2016 Jan;21(1):49-63.

29. van Dooren FEP, Nefs G, Schram MT, Verhey FRJ, Denollet J, Pouwer F. Depression and Risk of Mortality in People with Diabetes Mellitus: A Systematic Review and MetaAnalysis. PLOS ONE. 2013 Mar 5;8(3):e57058.

30. van Melle JP, de Jonge P, Spijkerman TA, Tijssen JGP, Ormel J, van Veldhuisen DJ, et al. Prognostic association of depression following myocardial infarction with mortality and cardiovascular events: a meta-analysis. Psychosom Med. 2004 Dec;66(6):814-22.

31. Wulsin LR, Vaillant GE, Wells VE. A systematic review of the mortality of depression. Psychosom Med. 1999 Feb;61(1):6-17.

32. DerSimonian R, Laird N. Meta-analysis in clinical trials. Control Clin Trials. 1986 Sep;7(3):177-88.

33. Higgins JPT, Thompson SG, Deeks JJ, Altman DG. Measuring inconsistency in metaanalyses. BMJ. 2003;327:557-560.

34. Egger M, Davey Smith G, Schneider M, Minder C. Bias in meta-analysis detected by a simple, graphical test. BMJ. 1997;315:629-34.

35. Altman DG, Bland JM. Interaction revisited: the difference between two estimates. BMJ. 2003 Jan 25;326(7382):219.

36. Hasin DS, Goodwin RD, Stinson FS, Grant BF. Epidemiology of major depressive disorder: results from the National Epidemiologic Survey on Alcoholism and Related Conditions. Arch Gen Psychiatry. 2005 Oct;62(10):1097-106.

37. Zimmerman M, Chelminski I, McGlinchey JB, Young D. Diagnosing major depressive disorder X: can the utility of the DSM-IV symptom criteria be improved? J Nerv Ment Dis. 2006 Dec;194(12):893-7.

38. Gullion CM, Rush AJ. Toward a generalizable model of symptoms in major depressive disorder. Biol Psychiatry. 1998 Nov 15;44(10):959-72.

39. Santor DA, Gregus M, Welch A. Eight Decades of Measurement in Depression. Meas Interdiscip Res Perspect. 2006 Jul;4(3):135-55. 
40. Zimmerman M, Martinez JH, Friedman M, Boerescu DA, Attiullah N, Toba C. How can we use depression severity to guide treatment selection when measures of depression categorize patients differently? J Clin Psychiatry. 2012 Oct;73(10):1287-91.

41. Fried EI, Nesse RM. Depression sum-scores don't add up: why analyzing specific depression symptoms is essential. BMC Med. 2015;13:72.

42. Kroenke K, Spitzer RL, Williams JBW. The PHQ-9. J Gen Intern Med. 2001 Sep;16(9):606-13.

43. Stafford L, Berk M, Jackson HJ. Validity of the Hospital Anxiety and Depression Scale and Patient Health Questionnaire-9 to screen for depression in patients with coronary artery disease. Gen Hosp Psychiatry. 2007 Oct;29(5):417-24.

44. van Steenbergen-Weijenburg KM, de Vroege L, Ploeger RR, Brals JW, Vloedbeld MG, Veneman TF, et al. Validation of the PHQ-9 as a screening instrument for depression in diabetes patients in specialized outpatient clinics. BMC Health Serv Res. 2010 Aug $12 ; 10: 235$.

45. Fann JR, Bombardier CH, Dikmen S, Esselman P, Warms CA, Pelzer E, et al. Validity of the Patient Health Questionnaire-9 in assessing depression following traumatic brain injury. J Head Trauma Rehabil. 2005 Dec;20(6):501-11.

46. Nyunt MSZ, Fones C, Niti M, Ng T-P. Criterion-based validity and reliability of the Geriatric Depression Screening Scale (GDS-15) in a large validation sample of communityliving Asian older adults. Aging Ment Health. 2009 May;13(3):376-82.

47. Phelan E, Williams B, Meeker K, Bonn K, Frederick J, LoGerfo J, et al. A study of the diagnostic accuracy of the PHQ-9 in primary care elderly. BMC Fam Pract. 2010 Sep $1 ; 11: 63$.

48. Stahl D, Sum CF, Lum SS, Liow PH, Chan YH, Verma S, et al. Screening for depressive symptoms: validation of the center for epidemiologic studies depression scale (CES-D) in a multiethnic group of patients with diabetes in Singapore. Diabetes Care. 2008 Jun;31(6):1118-9.

49. Lyness JM, Noel TK, Cox C, King DA, Conwell Y, Caine ED. Screening for Depression in Elderly Primary Care Patients: A Comparison of the Center for Epidemiologic StudiesDepression Scale and the Geriatric Depression Scale. Arch Intern Med. 1997 Feb 24;157(4):449-54.

50. Whooley MA, Wong JM. Depression and cardiovascular disorders. Annu Rev Clin Psychol. 2013;9:327-54.

51. Ye S, Muntner P, Shimbo D, Judd SE, Richman J, Davidson KW, et al. Behavioral mechanisms, elevated depressive symptoms, and the risk for myocardial infarction or death in individuals with coronary heart disease: the REGARDS (Reason for Geographic and Racial Differences in Stroke) study. J Am Coll Cardiol. 2013 Feb 12;61(6):622-30. 
52. Lev-Ran S, Le Strat Y, Imtiaz S, Rehm J, Le Foll B. Gender differences in prevalence of substance use disorders among individuals with lifetime exposure to substances: results from a large representative sample. Am J Addict. 2013 Jan;22(1):7-13.

53. Becker JB, Hu M. Sex Differences in Drug Abuse. Front Neuroendocrinol. 2008 Jan;29(1):36-47.

54. EATON WW, MUNTANER C, BOVASSO G, SMITH C. Socioeconomic Status and Depressive Syndrome: The Role of Inter- and Intra-generational Mobility, Government Assistance, and Work Environment. J Health Soc Behav. 2001 Sep;42(3):277-94.

55. Lorant V, Deliège $\mathrm{D}$, Eaton $\mathrm{W}$, Robert A, Philippot $\mathrm{P}$, Ansseau M. Socioeconomic inequalities in depression: a meta-analysis. Am J Epidemiol. 2003 Jan 15;157(2):98-112.

56. Boschloo L, van den Brink W, Penninx BWJH, Wall MM, Hasin D. Alcohol-use disorder severity predicts first-incidence of depressive disorders. Psychol Med. 2012 Apr;42(4):695703.

57. Nandi A, Glymour MM, Subramanian SV. Association among socioeconomic status, health behaviors, and all-cause mortality in the United States. Epidemiol Camb Mass. 2014 Mar;25(2):170-7.

58. Beck AT, Steer RA, Kovacs M, Garrison B. Hopelessness and eventual suicide: a 10-year prospective study of patients hospitalized with suicidal ideation. Am J Psychiatry. 1985 May;142(5):559-63.

59. Beck AT, Brown G, Berchick RJ, Stewart BL, Steer RA. Relationship between hopelessness and ultimate suicide: a replication with psychiatric outpatients. Am J Psychiatry. 1990 Feb;147(2):190-5.

60. Poorolajal J, Darvishi N. Smoking and Suicide: A Meta-Analysis. PLOS ONE. 2016 Jul 8;11(7):e0156348.

61. Hemenway D, Solnick SJ, Colditz GA. Smoking and suicide among nurses. Am J Public Health. 1993 Feb;83(2):249-51.

62. Miller M, Hemenway D, Bell NS, Yore MM, Amoroso PJ. Cigarette smoking and suicide: a prospective study of 300,000 male active-duty Army soldiers. Am J Epidemiol. 2000 Jun 1;151(11):1060-3.

63. Wilcox HC, Conner KR, Caine ED. Association of alcohol and drug use disorders and completed suicide: an empirical review of cohort studies. Drug Alcohol Depend. 2004 Dec 7;76 Suppl:S11-19.

64. Miller NS, Mahler JC, Gold MS. Suicide risk associated with drug and alcohol dependence. J Addict Dis. 1991;10(3):49-61. 